\title{
Active Learning Techniques to Promote Student Learning
}

\author{
Dubhashi SP ${ }^{1}$, Dalvi $\mathrm{SD}^{2}$, Kadam $\mathrm{SN}^{3}$, Kadam $\mathrm{NN}^{4}$ \\ ${ }^{1}$ Director (Academics), Professor and Head-Department of Surgery, Head-MGMIHS Unit of UNESCO \\ Chair in Bioethics, Navi Mumbai. \\ ${ }^{2}$ Vice Chancellor, MGM Institute of Health Sciences. \\ ${ }^{3}$ Medical Director and Former Vice Chancellor, MGM Institute of Health Sciences. \\ ${ }^{4}$ Controller of Examinations, MGM Institute of Health Sciences. \\ Corresponding Author: S.P. Dubhashi \\ Email: spdubhashi@gmail.com
}

\section{Introduction}

Survival in the 21 st century warrants certain radical changes in the existing education system. It is not about just "knowing" a fact, but it is the "application" of the knowledge into practice, which is the key to an optimal outcome. When one enters the medical college, the first thing that one is made to learn is to forget one's common sense 1]. At present, our curriculum itself is afflicted with several ailments. The Currriculopathies include: Curriculosclerosis, Curricular Hypertrophy, Curricular disthesia, Curricular ossification [2]. Medical Education in India remains a process of training "the doctors of tomorrow with today's curriculum and yesterday's teaching-learning methods" [3]. We need to meet the needs of students with a wide range of abilities, aptitudes, differing value systems and culture and make the students learn to apply their knowledge in "total" care of patients. Active learning techniques will lend fluidity in the teaching-learning process, making it an enjoyable experience for the faculty and students.

\section{Miller's Pyramid of Assessment}

Miller's Pyramid of Assessment (Fig, 1) provides a framework for assessing clinical competence in medical education and can assist clinical teachers in matching learning outcomes (clinical competencies) with expectations of what the learner should be able to do at any stage [4].

Knows forms the base of the pyramid and the foundation for building clinical competence.

Knows How uses knowledge in the acquisition, analysis, and interpretation of data and the development of a plan.

Shows How requires the learner to demonstrate the integration of knowledge and skills into successful clinical performance.

Does focuses on methods that provide an assessment of routine clinical performance.

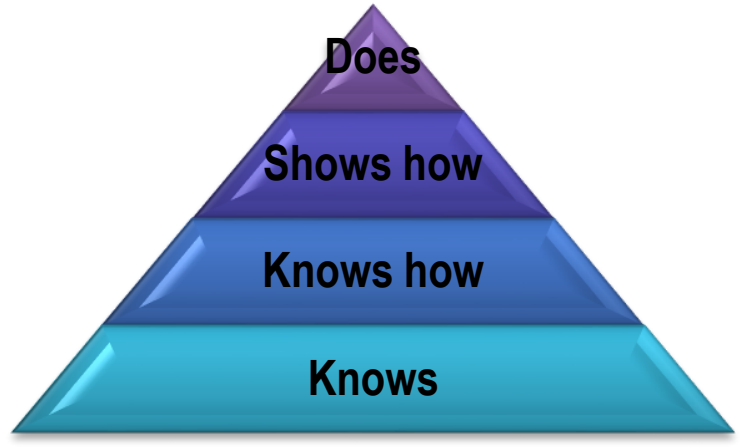

Fig. 1: Miller's Pyramid 


\section{Active Learning Techniques}

Active learning techniques involve students in doing things and make them think about the things they are doing. The students become proficient in skills by practicing them, rather than being a mute spectator to the skill - by listening to the teacher or by reading about the skill [5]. Active hands-on teaching strategies and learning activities are the need of the hour. Teaching strategies refer to the structure, system, methods, processes that a teacher uses during instruction. Learning activities are the teacher-guided instructional tasks and assignments for students.

Learning approaches can be surface or deep. A surface approach to learning is an intention to do the task with minimal effort, usually by rote memorization, without any attempt to relate the concepts to existing experiences. A deep approach evolves from the need to comprehend and seek meaning, with a critical evaluation of knowledge [6]. Active learning can engage students in and out of class, as an individual or in groups, with or without technical tools. This can help students to think creatively, express ideas through writing, interact in small groups, understand personal values and reflect upon the learning process.

A Content-driven Development Model divides the content into various sections to be covered over the course span and then plans for techniques of content delivery. A Systematic Learning-Centered Design Model focuses on systematic learning tools to develop solutions to learning objectives. The 5 Es (Engagae, Explore, Explain, Elaborate, Evaluate) Inquiry Framework is based on the concept that the students learn and retain knowledge when they have had an exposure of variety of experiences that are framed by the facilitator [7].

\begin{tabular}{|l|l|}
\hline Engage & $\begin{array}{l}\text { Capture the interest of the students and give them an opportunity to demonstrate } \\
\text { their prior knowledge }\end{array}$ \\
\hline Explore & $\begin{array}{l}\text { Facilitate activities that provide the students with an opportunity to explore the } \\
\text { skill / concept }\end{array}$ \\
\hline Explain & $\begin{array}{l}\text { Facilitator provides concepts to formulate explanations for the phenomenon that } \\
\text { the students have already experienced }\end{array}$ \\
\hline Elaborate & $\begin{array}{l}\text { Students are encouraged to apply knowledge for better understanding or better } \\
\text { demonstration of skill }\end{array}$ \\
\hline Evaluate & Review and Reflect on learning experiences \\
\hline
\end{tabular}

\section{Brainstorming}

It provides a large number of diverse ideas related to a chosen topic. Students can express their views without the fear of being criticized.

\section{Role Plays}

These engage students in real life case scenarios. They are short spontaneous or pre-decided assignments. They provide opportunities for critical observation of peers. They should be contentfocussed, match learning objectives and be relevant. They can convey the message very effectively.

\section{Problem-Based Learning}

It is self-directed learning. A case scenario, a teaching model, a histology slide can serve as triggers. The learning objectives are defined by a small group of students with the help of a facilitator. They are given sufficient time to interact and explore all learning resources. The second session provides them an opportunity to present their findings. The facilitator then fleshes out the key messages and helps to formulate the concept map.

\section{Fish Bowl}

The participant speakers are seated in the centre of the room with other participants sitting around them in a circle (active listeners), seeing their interaction in the fishbowl. The interactions are moderated by a facilitator. The participants will swap their roles in due course of discussion. 


\section{Mind Mapping}

It's a visual exercise to help students organize and structure complex content. It carves out a hierarchy of information to work out key components and their inter-relationship. There is a focus on a central idea, with branches to depict the importance of issues related to it.

\section{Peer-Assisted Learning}

Faculty evaluate and identify the students who need help with specific skills and determine the most appropriate students in the class to assist them with those skills. It expands the instructional resources, with positive and productive peer interaction. This approach helps the faculty to accommodate academic diversity.

\section{Interactive lectures}

These provide students with multiple brief opportunities for structured engagement. A short inclass activity is planned. Student-to-student talk is encouraged. Opportunities for conceptual clarifications are provided periodically within the lecture.

\section{Ward Rounds}

This time-tested approach is a powerful active teaching-learning tool. Faculty acts as a facilitator for structured case-based discussion for all domains of learning: cognitive, affective and psychomotor. This strategy is the best method to practice evidence-based medicine.

Debates and Quizzes make the learning environment vibrant and conducive to active learning.

\section{Infusing Humor}

This strategy should be used judiciously by the faculty and should convey the appropriate intended message.

\section{Conclusions}

The outcome of teaching-learning strategy revolves around three parameters: Comprehension, Analysis and Demonstration. Active learning techniques can provide students with greater responsibility for their own learning. The teacher assumes the role of a facilitator, who creates an environment conducive for active learning. This approach will foster several attributes: flexibility, creativity, pro-activeness, appropriate decision-making, effective communication and a spirit of team work.

\section{REFERENCES}

1. Holtzman NA. The interpretation of laboratory results: the paradoxical effect of medical training. J Clin Ethics 1991;2(4):241-3.

2. Abrahamson S. Diseases of the curriculum. Med Educ 1978;53(12):20-5.

3. Ananthakrishnan N. Medical education in India: is it still possible to reverse the downhill trend. Nat Med J India. 2010 Jan 1;23(3):156-60.

4. Ramani S, Leinster S. AMEE Guide no. 34: Teaching in the clinical environment. Medical teacher. 2008 Jan 1;30(4):347-64.

5. Harmin $M$, Toth $M$. Inspiring active learning: A complete handbook for today's teachers. ASCD; 2006.

6. Biggs JB. Approaches to the enhancement of tertiary teaching. Higher education research and development. 1989 Jan 1;8(1):7-25.

7. Bybee RW. Science for life \& living: An elementary school science program from Biological Sciences Curriculum Study. The American Biology Teacher. 1990 Feb 1;52(2):92-8.

Acknowledgements - Nil; Source of Funding - Nil; Conflict of Interest - Nil 